\title{
CELEBRANDO A NORMATIZAÇÃO DA VIDA: (RE)PENSANDO OS CORPOS INFANTIS ARBITRARIAMENTE GENERIFICADOS EM VÍDEOS DE “CHÁS DE REVELAÇÃO” DO YOUTUBE
}

\author{
Dilton Ribeiro Couto Junior ${ }^{\mathrm{i}}$ \\ Ivan Amaro ${ }^{\mathrm{ii}}$ \\ Renato Romeritto iii \\ Ruann Moutinho Ruani ${ }^{\text {iv }}$
}

\begin{abstract}
Resumo: Fruto de pesquisa de pós-doutorado em educação em andamento, o texto é focado em refletir sobre o enquadramento dos corpos infantis em categorias estáticas, hierarquizantes e binárias expressos em vídeos de "chás de revelação" publicizados no YouTube. Para isso, operamos de forma teórica e metodológica através da abordagem cartográfica e adotamos o YouTube como lócus de pesquisa, rede social que já se constitui como parte do cenário sóciotécnico contemporâneo. As narrativas presentes nos "chás de revelação" trouxeram alguns apontamentos reflexivos preliminares, incluindo a necessidade de problematizarmos as tradições culturais que reforçam a compreensão estereotipada do gênero desde os primeiros anos da criança.
\end{abstract}

Palavras-chave: YouTube; Normas regulatórias de gênero; Criança; Educação.

\section{CELEBRATING THE STANDARDIZATION OF LIFE: (RE) THINKING ARBITRARILY GENDERED CHILDREN'S BODIES ON YOUTUBE'S “GENDER REVEAL PARTIES" VIDEOS}

\begin{abstract}
As a result of a current postdoctoral research in Education, this paper focuses on reflecting on the framing of children's bodies in static, hierarchical and binary categories expressed in "gender reveal parties" videos posted on YouTube. For that, we use a mapping approach through a theoretical and methodological way, and we adopt YouTube as a place of research - a social network that is already part of the contemporary socio-technical scenario. The narratives presented in those "gender reveal parties" brought some preliminary reflective notes, including the need to problematize cultural traditions that reinforce the stereotyped comprehension of genre from the earliest years of childhood.
\end{abstract}

Keywords: YouTube; Gender regulatory norms; Child; Education.

2020 Bargas; Ayoub; Assaritti, Scarazzatto, Assis. Este é um artigo de acesso aberto distribuído sob os termos da Licença Creative Commons Atribuição Não ComercialCompartilha Igual (CC BY-NC-4.0), que permite uso, distribuição e reprodução para fins não comerciais, com a citação dos autores e da fonte original e sob a mesma licença 


\section{O SEXO DO BEBÊ EM DISPUTA: NOTAS INTRODUTÓRIAS}

Se sou homem ou mulher? Esta pergunta reflete uma obsessão ansiosa do ocidente. Qual? A de querer reduzir a verdade do sexo a um binômio. Eu dedico minha vida a dinamitar esse binômio. Afirmo a multiplicidade infinita do sexo!

Paul Beatriz Preciado

A gravidez, para muitas/os, é um processo envolto em grande ansiedade, principalmente, quando se quer "descobrir" o sexo do bebê. Desde o anúncio da gravidez, a mesma pergunta é proferida diversas vezes: “é menino ou menina?”. A partir daí, são lançadas suposições diversas sobre o corpo que ainda é apenas uma promessa (BENTO, 2011). A existência do corpo parece só adquirir inteligibilidade quando se anuncia o sexo do bebê. Conforme Bento (2011, p. 550), as palavras proferidas pela/o médica/o após o exame ecográfico têm o poder mágico de gerar expectativas que serão materializadas posteriormente em brinquedos, cores, modelos de roupas e projetos para o/a futuro/a filho/a. A partir dessa necessidade de conhecer o sexo do bebê, celebrações diversas se espalham e compõem os mais diversos contextos socioculturais.

Dessa forma, além dos famosos "chás de bebê", realizados próximo ao nascimento, os "chás de revelação", celebrações para revelar o sexo da criança, tornaram-se uma espécie de febre em todo o mundo. Imaginem a seguinte cena de um "chá de revelação" fictício, mas que retrata muito bem esse ritual de celebração da normatização da vida: um casal animado começa a festa agradecendo a presença de amigas/os e familiares em um evento criteriosamente planejado com o objetivo de descobrir o sexo de um bebê que ainda não nasceu. A primeira tarefa dada ao casal é estourar uma bexiga transparente, que contém uma pista, escrita em um pedaço de papel, indicando o próximo passo: "olhem debaixo da mesa". O rapaz, muito entusiasmado e curioso, se abaixa para verificar e descobre uma nova pista anotada em um pedaço de papel: "dê um tapa na cara do seu tio masoquista". A esposa se surpreende com a existência de um tio masoquista na família e descobre que é o tio Dudu. “Um, dois, três e... pa!”, Dudu leva um tapa na cara para dar prosseguimento ao rito de descobrimento do sexo do bebê. Uma nova pista é entregue ao casal, que pede que a esposa, grávida, "faça cinco flexões". A próxima pista diz que "para ter a

Revista Interinstitucional Artes de Educar. Rio de Janeiro, V. 6, N.2- pág. 469-488 maio-agosto de 2020: "Bebês e crianças: cultura, linguagem e políticas"

DOI: 10.12957/riae.2020.46467 
próxima instrução e não ficar à míngua beije seu sogro de língua". Essas celebrações levam a questionar a arbitrariedade das atividades planejadas e que reforçam o enquadramento de um bebê em um único gênero a partir de seu órgão genital. Entretanto, conforme pontua Butler (2017, p. 37), embora venhamos ao mundo em meio a normas obrigatórias, elas nem sempre nos ordenam e nem sempre emergimos da imagem do que é esperado pelos significantes "homem" $e$ “mulher”. Em meio a tapas na cara do tio Dudu e flexões realizadas pela esposa, as atividades planejadas para o casal grávido continuam no "chá de revelação".

Após o beijo de língua entre o esposo e o sogro, o casal recebe novo papelzinho, que diz: "para obter a próxima pista brinque de espada com sua ginecologista". A esposa, com a espada na mão, fica na dúvida sobre como brincar e a ginecologista logo inicia o combate. Em coro, as/os convidadas/os presentes gritam: "briga, briga, briga!", mas não por muito tempo porque a ginecologista é atingida no braço e começa a sangrar. Depois de uma discussão entre o casal e o esposo da ginecologista, devido à violência da brincadeira, dois policiais entram abruptamente e perguntam enfaticamente: “que porra é essa?!". O esposo leva um tiro no peito, deixando a esposa perplexa e chorosa. Em seguida, o policial pergunta educadamente: "A senhora pode por gentileza colocar a mão no ferimento de seu marido?". Ela coloca a mão no ferimento e descobre, através da bala, que está grávida de uma menina. Em meio ao desespero da esposa por conta da morte do marido, embora muito feliz com a descoberta de que está grávida de uma menina, a história de ficção chega ao fim.

O vídeo descrito acima, intitulado "Chá de Revelação", foi produzido pelo canal Parafernalha, encontra-se disponível na rede social YouTube (no link: https://bit.ly/2SoJlpo) e foi postado em novembro de 2018. Um mês depois, já havia sido acessado cerca de 900 mil vezes. O canal contava, à época, com aproximadamente 10 milhões de internautas inscritas/os. Repleto de muito humor, consideramos um vídeo importante para dar início às reflexões deste texto, porque nos faz (re)pensar o quanto as normas regulatórias de gênero atravessam as experiências sociais das pessoas, envolvendo também os corpos infantis ainda em gestação.

A seguir, destacamos parte da mensagem que é apresentada às/aos internautas que acessam o vídeo e traduz resumidamente a intenção de se desenvolver um trabalho que parodia os absurdos da cena cotidiana envolvendo os "chás de revelação": "mas vocês já viram o que anda rolando por aí? O YouTube está repleto de vídeos desses chás e são loucos, tão loucos que foi bem difícil escrever algo que tivesse mais humor e mais falta de sanidade do que a realidade

Revista Interinstitucional Artes de Educar. Rio de Janeiro, V. 6, N.2- pág. 469-488 maio-agosto de 2020: "Bebês e crianças: cultura, linguagem e políticas"

DOI: 10.12957/riae.2020.46467 
que já nos cerca". Afinal, não há como negar o quão desafiante é parodiar determinadas cenas cotidianas que, num primeiro olhar, nos faltam palavras para descrever/refletir a respeito. Nossa intenção com este texto é refletir sobre processos de desnaturalização de práticas sociais culturalmente concebidas como usuais, questionando/problematizando a normatização da vida por detrás de discursos-atos, aparentemente inofensivos, mas que colocam em xeque as múltiplas formas de existência que não são alinhadas com a organização social binária (mulher/homem, homossexual/heterossexual, para citar alguns).

Não há como desconsiderarmos a popularização dos "chás de revelação" no Brasil, da preocupante reiteração das normas regulatórias de gênero no cotidiano da educação de crianças e da facilidade com a qual podemos produzir e compartilhar nossas próprias produções audiovisuais em/na rede com outras/os usuárias/os geograficamente dispersas/os. É dentro deste panorama que tecemos algumas considerações não conclusivas sobre o enquadramento dos corpos infantis em categorias binárias (menino/menina) expressos em vídeos de "chás de revelação" publicizados na rede social YouTube.

Pesquisar questões envolvendo a temática gênero e infância, no contexto da rede social YouTube, nos traz como desafio pensar no quanto a normatização dos corpos, gêneros e sexualidades passaram a ocupar outros espaços-tempos, cujas práticas sociais vêm, cada vez mais, sendo mediadas pelas tecnologias digitais em rede. Os corpos dessas crianças, embora ainda em processo de gestação no útero, já se constituem enquanto protagonistas dos "chás de revelação", cuja popularidade é percebida por meio da intensa produção de vídeos compartilhados nas diversas redes sociais. Uma das características mais notáveis dessas produções é a insistente correlação entre menino-azul e menina-rosa, evidenciando uma normatização binária que demarca o enquadramento dos gêneros em atributos culturalmente construídos. Para Bento (2011), todas as expectativas do "ser menino ou ser menina" centram-se em um conjunto de referenciais simbólicos que vão, culturalmente, definindo estes corpos como femininos ou masculinos. Na rede, é possível encontrar diversas "dicas" de como organizar os chás de revelação e percebe-se de forma muito contundente as cores rosa e azul como naturais para a definição do sexo do bebê.

Para Bello e Felipe (2010, p. 178), as pessoas estão de tal forma absorvidas por essa maneira naturalizada de pensar o mundo, a partir do trinômio gênero-sexo-sexualidade, que buscam de forma muito intensa garantir a heterossexualidade desde a infância. Entretanto, cada 
nascimento revela certa imprevisibilidade, porque embora a criança possa pertencer a uma família com práticas heteronormativas, nem sempre seu modo de ser e estar no mundo será alinhado com a forma hegemônica de se constituir homem ou mulher. De forma alguma os "chás de revelação" esperam algo diferente da relação menino-pênis-heterossexualidade ou meninavagina-heterossexualidade. Muito embora os movimentos e posições de dissidência sejam constituintes das relações humanas, é preciso reiterar práticas-discursos através de esforços e empreendimentos para manter intacta a supremacia das normas regulatórias de gênero desde a infância (LOURO, 2009).

Este breve panorama é o pano de fundo deste texto, fruto de pesquisa de pós-doutorado em educação em andamento que vem investigando as experiências sociais de sujeitos que construíram trajetórias marcadas por movimentos e posições de inconformidade às normas de gênero e sexualidade, com ênfase nas lembranças de suas infâncias. A partir da interlocução com autoras/es do campo de estudos de gênero e sexualidade que vêm centralizando seus esforços em torno do questionamento das normas de gênero, este trabalho busca problematizar o enquadramento dos corpos infantis em categorias estáticas, hierarquizantes e binárias expressos em vídeos de "chás de revelação" publicizados no YouTube.

Na próxima seção, apresentamos os caminhos teórico-metodológicos da pesquisa e, em seguida, analisamos alguns dos vídeos de "chá de revelação" do YouTube que foram selecionados para integrar nossas reflexões. Por fim, realizamos algumas breves considerações voltadas para questionar a produção e reiteração de práticas sociais responsáveis pela naturalização de formas cristalizadas de entender o que é ser "menino" e "menina", trazendo algumas contribuições para se (re)pensar o cotidiano da educação de crianças.

\section{A CARTOGRAFIA COMO CAMINHO TEÓRICO-METODOLÓGICO: O YOUTUBE COMO LÓCUS DE PESQUISA}

As produções audiovisuais digitais constituem-se parte do cenário sócio-técnico contemporâneo denominado de cibercultura (SANTOS; CARVALHO, 2018). Por meio do uso de algum dispositivo com acesso à internet, usuárias/os de todos os cantos do planeta podem acessar e produzir em/na rede novas informações, entrando em contato com uma rica produção

Revista Interinstitucional Artes de Educar. Rio de Janeiro, V. 6, N.2- pág. 469-488 maio-agosto de 2020: "Bebês e crianças: cultura, linguagem e políticas"

DOI: 10.12957/riae.2020.46467 
audiovisual que retrata os acontecimentos sociais de um determinado tempo-espaço (FERREIRA; COUTO JUNIOR, 2018; SANTOS; WEBER, 2013).

Os computadores de mesa (desktops), cada vez mais, dão espaço aos leves laptops, tablets e smartphones, permitindo o acesso cada vez mais dinâmico a uma quantidade aparentemente inesgotável de informações (imagens, vídeos, sons etc) que se encontram disponíveis para as/os usuárias/os de redes sociais (COUTO JUNIOR, 2013). As diversas informações digitais produzidas e compartilhadas na rede mundial de computadores vêm constituindo-se como um importante material empírico de análise para as pesquisas das ciências humanas e sociais. No campo da Educação, cabe citar aqui a) o trabalho de Macedo (2014), que investigou as experiências infantis nas redes sociais Orkut e Facebook; b) a pesquisa de Ferreira (2014), que buscou conhecer a forma como os dispositivos digitais móveis mediam processos de ensinar-aprender; e c) o estudo de Couto Junior (2013), que adotou o Facebook como lócus de investigação, focalizando os processos interativos e colaborativos de ensinar-aprender estabelecidos entre jovens internautas geograficamente dispersas/os.

No que se refere à produção científica que intersecciona gênero e sexualidade em articulação com as práticas sociais mediadas pelas tecnologias digitais em rede, cabe destacar a) o trabalho de Carvalho, Pocahy e Santos (2017), que, no contexto das dinâmicas ciberculturais, discutiram a necessidade de refletir sobre uma formação docente não fascista em parceria com estudantes do curso de pedagogia da Universidade do Estado do Rio de Janeiro (UERJ); b) a pesquisa de Couto Junior e Oswald (2017), que investigou o protagonismo político de jovens no Facebook, durante as manifestações de 2013, no Brasil, quando confeccionaram colaborativamente um cartaz que questionava o projeto de Lei popularmente conhecido como "cura gay"; c) o trabalho de Couto Junior e Brito (2018), que investigou a apropriação da rede social digital como espaço de resistência por jovens autoproclamadas/os não heterossexuais, focalizando seus esforços ciberativistas na crítica às heteronormas; e d) o estudo de Carvalho, Roseno e Pocahy (2017), que pesquisou as novas sociabilidades que emergem com as redes sociais online, atentando-se para uma discussão interseccional abarcando os marcadores sociais de gênero, sexualidade, raça e geração.

Os trabalhos acima mencionados evidenciam o grande potencial da internet como lócus de pesquisa, principalmente as redes sociais digitais, na medida em que permitem a intensa produção e compartilhamento de informações pelas/os próprias/os usuárias/os. Pesquisar o tema

Revista Interinstitucional Artes de Educar. Rio de Janeiro, V. 6, N.2- pág. 469-488 maio-agosto de 2020: "Bebês e crianças: cultura, linguagem e políticas"

DOI: 10.12957/riae.2020.46467 


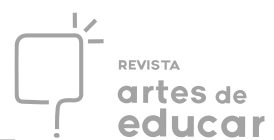

dos "chás de revelação" na internet permitiu lançar um olhar de alteridade sobre a forma com a qual grupos de sujeitos relacionam-se com acontecimentos socioculturais de uma época. Com esse desafio em mente, nos apropriamos da cartografia como princípio ético-estético-político com a intenção de questionar os jogos de saber-poder considerados inquestionáveis (COUTO JUNIOR; POCAHY, 2017). Investigar os vídeos sobre "chá de revelação" publicizados na internet por meio da abordagem cartográfica constitui-se como um convite para que possamos desestabilizar verdades culturalmente construídas e que são reiteradas cotidianamente através das práticas sociais.

Nos inspiramos no trabalho de Carvalho, Roseno e Pocahy (2017), para quem propõem a cartografia em tempos de cibercultura. De acordo com os autores, as práticas sociais mediadas pelo digital em rede se constituem uma arena cultural, se abrindo tanto à produção de regulações quanto de formas de resistência. Não se está 'fora' de uma zona de saber-poder, joga-se apenas outramente com os termos que a cultura impõe como viáveis e possíveis (p. 5). Nessa linha de pensamento, adentrar no contexto das dinâmicas culturais, mais especificamente na rede social YouTube, significa reconhecermos a importância de (re)criarmos estratégias metodológicas que possam evidenciar as novas relações de saber-poder engendradas pela emergência do digital em rede. Em tempos de dinâmicas comunicacionais digitais em/na rede, reconhecemos a importância da cartografia para pensar nos espaços por onde outros arranjos $e$ hierarquias podem se (re)estabelecer, agora desde outros fluxos semióticos, ético, estéticos e políticos insurgentes na cibercultura (CARVALHO; ROSENO; POCAHY, 2017, p. 5).

Os "chás de revelação" nasceram de uma demanda social que encontrou elementos importantes na cultura em prol da celebração do sexo do bebê que ainda virá ao mundo. Esses elementos culturais são importantes na presente investigação, pois buscamos tensionar as normas regulatórias de gênero com a intenção de melhor compreender os processos de generificação dos corpos infantis nesses "chás". Somando-se a isso, o uso da cartografia como referencial teóricometodológico se justifica por se tratar de uma abordagem que possibilita buscar estratégia de análise crítica e ação política, olhar crítico que acompanha e descreve relações, trajetórias, formações rizomáticas, a composição de dispositivos, apontando linhas de fuga, ruptura e resistência (PRADO FILHO; TETI, 2013, p. 47). Entendendo que as interações sociais vêm cada vez mais ocorrendo através dos fluxos informacionais digitais, cabe olharmos atentamente para os discursos (cishetero)normativos ${ }^{\mathrm{v}}$ que encontraram nas redes sociais um espaço fértil para sua 
propagação. No entanto, não podemos desconsiderar o pensamento foucaultiano, para quem aponta que em toda relação de poder com o mínimo de liberdade, há resistência (FOUCAULT, 2014). Diante de nosso compromisso ético em tratar do tema gênero e infância neste texto, entendemos que a prática cartográfica auxilia na tessitura de reflexões que se constituem enquanto um ato de resistência porque favorecem a reflexão sobre a normatização dos corpos infantis arbitrariamente generificados pelas práticas socioculturais hegemônicas.

No que se refere aos procedimentos metodológicos, optamos pela análise das narrativas digitais presentes nos três vídeos de "chás de revelação" mais visualizados do YouTube. Para isso, no mecanismo de busca da interface digitamos "chá de revelação de bebê" e acionamos o filtro para organizar os vídeos por ordem de visualização. Os vídeos selecionados, apresentados no quadro abaixo, foram compartilhados na rede em 2017 e apresentam, cada um, mais de três milhões de visualizações. Além desses dados, outros aspectos que julgamos importantes, como o número de comentários realizados em cada vídeo, bem como o link de acesso a cada um deles, encontram-se listados abaixo:

Quadro 1 - Vídeos de "chá de revelação" do YouTube analisados

\begin{tabular}{|c|c|c|}
\hline Vídeo 1 & Vídeo 2 & Vídeo 3 \\
\hline $\begin{array}{c}\text { Título: E o nosso neném é... CHÁ } \\
\text { REVELAÇÃO } \triangleright\end{array}$ & $\begin{array}{c}\text { Título: CHÁ DE REVELAÇÃO - } \\
\text { Gabriela Almeida }\end{array}$ & $\begin{array}{c}\text { Título: chá de revelação incrível } \\
\text { papai desmaia ao saber sexo do } \\
\text { bebê, leia descrição }\end{array}$ \\
\hline $\begin{array}{l}\text { - } \quad \text { Canal: Taciele Alcolea } \\
\text { - } \quad \text { Duração do vídeo: } 19 \mathrm{~min}, 49 \mathrm{~s} \\
\text { - } \quad 32.400 .000 \text { visualizações } \\
\text { - } \quad \text { Data de postagem do vídeo: } \\
\text { 03/12/2017 } \\
\text { - } \quad \text { Link de acesso do vídeo: } \\
\text { https://bit.ly/2BI5mXU }\end{array}$ & $\begin{array}{ll}\text { - } & \text { Canal: Gabriela Almeida } \\
\text { - } & \text { Duração do vídeo: } 7 \text { min, } 14 \mathrm{~s} \\
\text { - } & \text { 2.400.000 visualizações } \\
\text { - } & \text { Data de postagem do vídeo: } \\
& \text { 13/03/2017 } \\
\text { - } & \text { Link de acesso do vídeo: } \\
& \text { https://bit.ly/2UsJU3y }\end{array}$ & $\begin{array}{ll}\text { - } & \text { Canal: fortes emoçoes } \\
\text { - } & \text { Duração do vídeo: } 5 \mathrm{~min}, 40 \mathrm{~s} \\
\text { - } & 3.3000 \text { comentários } \\
\text { - } & \text { Data de postagem do vídeo: } \\
& \text { 22/10/2017 } \\
\text { - } & \text { Link de acesso do vídeo: } \\
& \text { https://bit.ly/2L5BXNt }\end{array}$ \\
\hline
\end{tabular}

Fonte: dados da pesquisa coletados em dezembro de 2018 na rede social YouTube

Não é nossa intenção aqui esgotar todas as reflexões possíveis a partir das narrativas digitais presentes nos três vídeos, pois a escrita do pesquisador consolida a criação de conceitos cuja pretensão é criar zonas provisoriamente estáveis de pensamento sobre uma dada realidade (JOBIM E SOUZA; ALBUQUERQUE, 2012, p. 116). Essa perspectiva nos convida a colocar em prática um olhar interpretativo alteritário sobre os acontecimentos sociais sem a intenção de

Revista Interinstitucional Artes de Educar. Rio de Janeiro, V. 6, N.2- pág. 469-488 maio-agosto de 2020: "Bebês e crianças: cultura, linguagem e políticas"

DOI: 10.12957/riae.2020.46467 
fornecer a última palavra, mas proporcionar elementos reflexivos que auxiliam a (re)pensar a produção de conhecimento em torno dos atravessamentos das normas regulatórias de gênero expressos nos vídeos sobre o "chá de revelação".

\section{“ELA AINDA NÃO SABE QUEM SOU EU. LOGO, TODOS SABERÃO": ADENTRANDO O CAMPO DA INTELIGIBILIDADE CULTURAL}

Os processos comunicacionais engendrados pela internet permitem a produção e o compartilhamento de informações para outras pessoas geograficamente dispersas, conforme discutido anteriormente. Com o uso de equipamentos conectados à internet, somos produtoras/es em potencial de informação digital, garantindo que nossas narrativas sejam difundidas através das dinâmicas comunicacionais interativas da internet. Neste contexto, buscamos conhecer um pouco da produção audiovisual compartilhada no YouTube sobre os "chás de revelação", comemorações comumente presentes na vida cotidiana familiar que permitem profícuas reflexões sobre a reiteração das normas regulatórias de gênero em torno dos corpos dos bebês ainda em gestação.

Como profissionais do campo Educacional no Brasil, não podemos deixar de mencionar nossa preocupação em torno do fato de que é a anatomia do corpo que vem determinando o gênero de uma pessoa, com as práticas sociais (cishetero)normativas impondo uma única forma de ser menino/homem ou menina/mulher. Como pesquisadores, essas questões nos interpelam a estranharmos o que é aceito como normal (MEYER, 2014, p. 60), implicando-nos na tarefa de problematizar os acontecimentos sociais cotidianos. Se as crianças são interpeladas constantemente a agirem conforme o gênero ao qual foi atribuído durante o nascimento, suas margens de liberdade tornam-se mais estreitas em função de toda uma rede de vigilância e punição estabelecida em torno de seus corpos (FELIPE, 2007). Nesse contexto, um de nossos desafios vem sendo investigar quais masculinidades e feminilidades são (mais e menos) valorizadas no cotidiano da educação básica (e para além dela), focalizando nossos investimentos reflexivos em torno da produção e reiteração de discursos responsáveis pela desqualificação de determinados grupos de sujeitos.

Algumas das narrativas dos "chás de revelação" selecionadas a seguir refletem sobre o encontro de familiares em eventos planejados com a intenção de celebrar a chegada da criança

Revista Interinstitucional Artes de Educar. Rio de Janeiro, V. 6, N.2- pág. 469-488 maio-agosto de 2020: "Bebês e crianças: cultura, linguagem e políticas"

DOI: 10.12957/riae.2020.46467 
ao mundo. Esses eventos apresentam atividades realizadas em parceria com amigas/os e familiares e envolvem momentos de confraternização voltados para a "revelação" do gênero de um bebê que ainda está em desenvolvimento no útero.

\section{- Vídeo 1 -}

[Amiga da família lê uma mensagem sobre a gravidez do casal, contada sob o ponto de vista do bebê] Papai e mamãe ficaram muito felizes e surpresos. A família precisava saber. Foi tudo uma grande surpresa emocionante. Hoje estão todos reunidos aqui: papai, mamãe, familiares e amigos. Eu já sei quem sou, mas como mamãe e eu gostamos de uma surpresinha, ela ainda não sabe quem sou eu. Logo, todos saberão.

Adentrar o campo da inteligibilidade cultural significa dar nome e forma a alguma coisa, que passa a ser melhor compreendida por determinado grupo social. Isso fica evidente no entendimento da amiga da família, no excerto acima, quando escreveu a mensagem, narrada sob o ponto de vista do bebê: "ela [mãe] ainda não sabe quem sou eu. Logo, todos saberão". Nessa linha de pensamento, o sujeito só se torna alguém quando um gênero lhe for atribuído, reiterando a ideia de que as crianças são educadas pelos adultos a partir das normas dos gêneros inteligíveis. Ou seja, os comportamentos, os gostos, as características de desenvolvimento [que demarcam os gêneros] são reforçadas direta ou indiretamente no cotidiano (SILVA JUNIOR; CAETANO; GOULART, 2018, p. 99). Se o corpo é circunscrito no contexto de normas inteligíveis, nos preocupam todas as vidas que, por ventura, desviam-se das práticas e ações hegemônicas, performatizando gêneros em inconformidade com as normas regulatórias. Essas questões nos convidam a refletir sobre as consequências sociais da vigilância de todos os corpos infantis, constantemente na mira dos olhares (cishetero)normativos antes mesmo do nascimento. A definição do sexo do bebê parece funcionar como um batismo que permite ao corpo adentrar na categoria "humanidade” (BENTO, 2011, p. 551). Dessa forma, a enunciação "é uma menina" não descreve a menina, mas cria um vasto campo de expectativas para o corpo que foi enunciado como menina. A linguagem é, portanto, produtora de determinada rede de significados que materializa dada realidade. Assim, ao proferirmos os vocábulos "menino/menina", não estamos retratando uma situação, mas estamos produzindo masculinidades e feminilidades condicionados à genitália (BENTO, 2011).

Revista Interinstitucional Artes de Educar. Rio de Janeiro, V. 6, N.2-pág. 469-488 maio-agosto de 2020: "Bebês e crianças: cultura, linguagem e políticas" 
O próximo fragmento, também extraído do vídeo 1, apresenta outros elementos de reflexão que merecem destaque:

\begin{abstract}
- Vídeo 1 -
Amigo da família: Eu já tenho convicção, claro, que vai ser menina, por isso vim [referindo-se à cor da blusa] de rosa, claro... com certeza [é menina].

Amiga da família: eu não falei nada, não falei para ela se acho que é menina ou menino. Estou neutra, ela [a moça grávida] sabe disso. Eu sonhei antes dela engravidar que era uma menininha, mas eu estou super quietinha, neutra. O importante é que venha com saúde.
\end{abstract}

A forma como os "chás de revelação" são geralmente organizados exprimem o quanto as dinâmicas culturais colocam em produção e funcionamento os sistemas e códigos de significação que permitem atribuir sentido aos corpos generificados e sexuados que vamos (con)formando $e$ com os quais nos defrontamos no mundo em que vivemos e nos movimentamos (MEYER, 2014, p. 54). Mesa de doces enfeitadas com as cores azul/rosa, além das vestimentas das/os familiares e amigas/os, para citar alguns exemplos, fornecem pistas que apontam para o retrato de uma sociedade calcada dentro de uma lógica binária em se tratando do marcador social de gênero (LOURO, 2009). Não buscamos respostas prontas e conclusivas para essas questões, simplesmente questionamos a forma com a qual as cores são adotadas para circunscrever e reiterar o gênero da criança desde a infância.

Somando-se a isso, a ideia da "saúde" mencionada pela amiga da família no fragmento acima ("O importante é que venha com saúde") nos convida a tecer reflexões sobre o que poderíamos considerar como um corpo saudável. Para Miskolci (2006, p. 687), um corpo "saudável" tem de ser esbelto, pois a magreza (no ponto certo) é vista como prova de disciplina corporal e alimentar, de uma mente ativa e sob controle, enquanto o gordo é visto como um compulsivo, um descontrolado. Além disso, cabe destacarmos o marcador geração/idade para uma melhor compreensão do que hoje pode ser considerado um corpo com saúde. De um lado os corpos das crianças e dos jovens, vistos como sendo cheios de energia e criatividade, e do outro lado o corpo de uma pessoa mais velha, comumente caracterizado de forma negativa através de características físicas como os cabelos brancos, a falta de cabelos (calvície) e as rugas (GUIZZO; BECK, 2014). Dito isso, cabe frisar o quanto nossos corpos são atravessados por diferentes 
marcadores de identidade e diferença que evidenciam um empreendimento social colocado em funcionamento para diferenciar, depreciar, agrupar, nomear e classificar os diversos grupos (GUIZZO; BECK, 2014, p. 310) de sujeitos, separando os "saudáveis" dos demais. De forma preliminar, poderíamos afirmar que, no contexto do "chá de revelação", desejar que a criança "venha com saúde" implica aspirar que a aparência física e a saúde mental da criança estejam alinhadas com as expectativas sociais das/os amigas/os e familiares, dentro daquilo que se atribui como normalidade.

O próximo fragmento narrativo, extraído do vídeo 2, mostra parte da conversa estabelecida entre um casal grávido e sua primeira filha durante a realização de um "chá de revelação". A singela comemoração foi planejada para que a primeira filha do casal pudesse conhecer o gênero do bebê ainda em gestação.

\section{- Vídeo 2 -}

Filha: Que legal, uma festa!

Mãe: Mas essa não é qualquer festa.

Filha: [Olha para o bolo e pergunta] Mamãe, é um bolo de massinha?

Mãe: Não, filha, é um bolo de verdade.

Filha: Eu posso abrir?

Mãe: Você sabe o que é esse bolo?

Filha: Não sei.

Mãe: Esse é um bolo de chá de revelação.

Filha: $a h$ ?

Mãe: Você sabe o que significa?

Filha: Não.

Mãe: Que hoje você vai descobrir se o bebê que a mamãe está esperando é uma menina ou um menino.

Pai: Que será? Que será?

Mãe: $O$ que você acha que é?

Filha: Eu acho que é uma menininha.

Mãe: É?

Pai: Por que você acha que é uma menininha?

Filha: É porque eu gosto de menina.

Mãe: É, filha? Mas e se for um menino, você vai ficar triste?

Filha: Claro que não, vou gostar.

Mãe: Para quem você pediu uma menina?

Filha: Para o Papai do Céu.

Mãe: Então vamos abrir este bolo.

Revista Interinstitucional Artes de Educar. Rio de Janeiro, V. 6, N.2- pág. 469-488 maio-agosto de 2020: "Bebês e crianças: cultura, linguagem e políticas" 
A filha do casal, desde muito nova, já começa a participar das tradições familiares, incluindo aprender sobre os diferentes aspectos dos "chás de revelação" na medida em que é filmada pelos pais. Ao perguntar para a filha "Você sabe o que significa [chá de revelação]?”, a mãe coloca em prática o desejo de ensinar para a menina questões culturais envolvendo a interface corpo-gênero. É justamente a partilha das experiências sociais que permite a (re)configuração das dinâmicas culturais, possibilitando que diferentes sujeitos sejam capazes de reconhecerem-se (ou não) como membros de um grupo (MEYER, 2014). Ao mesmo tempo, cabe considerar que esse sentimento de pertencimento social evidencia o quanto a cultura funciona como um processo arbitrário, uma vez que cada grupo pode viver de forma diferente ou atribuir um significado diferente a um mesmo fenômeno ou objeto (MEYER, 2014, p. 54). As convenções culturais são fundantes nas relações humanas, por isso tamanho é nosso desafio de desconstruir determinadas normas/condutas, mesmo quando, através da linguagem, certos costumes naturalizam e desqualificam determinadas formas de ser e estar no mundo.

A narrativa acima traz ainda a presença da religião no atravessamento da inter-relação gênero-corpo. Sobre isso, a menina afirmou que rezou "Para o Papai do Céu" ao ser questionada pela mãe sobre o gênero da criança em gestação ("Para quem você pediu uma menina?"). O próximo fragmento, extraído do vídeo 3, também evidencia a forte presença do marcador religião durante o "chá de revelação":

\section{- Vídeo 3 -}

Pai: Primeiro eu quero falar algumas coisas. Primeiro eu quero agradecer a presença de todos, [agradecer a presença] da minha família e da família da Letícia. Quero agradecer a Pat, que fez o almoço para nós, tá?

[Todas/os vibram e aplaudem]

Pai: Independente do sexo que vim, vai ser bem vindo. Se for menina ou menino [vai ser bem vindo]. Vamos orar.

Mãe da grávida: Quero agradecer a Deus em primeiro lugar, por tudo. Por cada um que chegou aqui [no chá de revelação] em segurança que Deus trouxe. Por cada um que não pôde vim. [se emociona] Que essa criança seja bem vinda. Em nome de Jesus, independente do sexo. [...] Agradeço a Deus por essa oportunidade de ver todo mundo reunido. [...] Deus preparou tudo isso. Amém.

Toda família em coro: corta! Corta! Corta! [bolo]

É menino!

[Mãe entrega uma carta para o pai ler]

Pai: ai, amor, o que é isso?

[pai desmaia]

Revista Interinstitucional Artes de Educar. Rio de Janeiro, V. 6, N.2-pág. 469-488 maio-agosto de 2020: "Bebês e crianças: cultura, linguagem e políticas" DOI: $10.12957 /$ riae.2020.46467 
Pedir que venha uma menina "Para o Papai do Céu" (vídeo 2) e "agradecer a Deus em primeiro lugar, por tudo" (vídeo 3) durante os "chás de revelação" evidenciam o quanto há a forte influência da religião nas práticas culturais. Historicamente, não há como desconsiderar a presença dos fundamentos religiosos nas tradições socioculturais brasileiras. Nos últimos anos, todavia, um cenário bastante alarmante vem se configurando com o crescimento dos grupos denominados ultraconservadores, que atuam de forma bastante intensa para a manutenção de uma ordem social que busca manter intacta a hegemonia dos padrões (cishetero)normativos (PEIXOTO, 2018). De acordo com Bento (2011), os discursos religiosos no Brasil atuam na constituição das subjetividades, incidindo também sobre a forma como as condutas de gênero são produzidas e reiteradas através da ideia de que seria pecaminoso não agir conforme as expectativas sociais impostas pelas normas regulatórias. No caso dos grupos ultraconservadores, evocar constantemente os preceitos religiosos em defesa dos "velhos costumes" implica desconsiderar a vivacidade das dinâmicas culturais, silenciando vozes que, historicamente, vêm demandando constantemente o direito de existir.

Os “chás de revelação" são manifestações culturais atravessadas por diferentes marcadores sociais de identidade de diferença. A nosso ver, essas comemorações celebram a normatização da vida da criança ao gerar uma expectativa social considerável para todas/os aquelas/es que participam ativamente do convívio de determinado grupo familiar. Ornamentos, vestimentas, convites e comida, para citar alguns itens importantes, são criteriosamente escolhidos para fazer dessa celebração um acontecimento. Não nos surpreende que, ao final do vídeo 3, ao ficar sabendo do gênero da criança pela cor do recheio do bolo (azul), o esposo desmaia assim que começa a se preparar para ler uma carta entregue a ele pela esposa. Agora que o gênero foi revelado, o que era uma abstração passa a ter concretude. O feto já não é feto, é um menino ou uma menina (BENTO, 2011, p. 550). Com essa revelação, novas expectativas sociais serão geradas em torno da vida de um bebê que, embora esteja em gestação, chegará ao mundo com muitos de seus primeiros passos já planejados.

A partir das narrativas analisadas, percebemos que diferentes discursos e significados podem contribuir (e têm contribuído) para produzir desigualdades entre homens e mulheres, garotos e garotas, moças e rapazes e reforçar distinções (PARAÍSO, 2014, p. 32-33). Em função

Revista Interinstitucional Artes de Educar. Rio de Janeiro, V. 6, N.2-pág. 469-488 maio-agosto de 2020: "Bebês e crianças: cultura, linguagem e políticas" 
disso, nos interessa (re)pensar o quanto a produção e reiteração dos discursos trazem implicações diretas sobre a forma como pensamos/agimos, ou seja, nos convidam a refletir sobre como vimos pensando/agindo em um determinado tempo e espaço (MEYER, 2014). Consequentemente, essas questões trazem implicações diretas para o campo Educacional, conforme discutiremos brevemente a seguir.

\section{EDUCAÇÃO, GÊNERO E INFÂNCIA: BREVES CONSIDERAÇÕES (IN)CONCLUSIVAS}

Como profissionais do campo Educacional implicados com o planejamento de estratégias voltadas para o enfrentamento das normas regulatórias de gênero em sala de aula, não podemos ignorar a quantidade significativa de materiais produzidos e compartilhados na rede por usuárias/os de todos os cantos do mundo e que evidenciam a reiteração cotidiana dessas normas. Esses materiais, disponíveis principalmente na forma de imagens, vídeos e sons, retratam a complexidade das práticas cotidianas, nos convidando a (re)pensar as experiências infantis em articulação com o marcador social gênero. Atribuir interpretações analíticas aos vídeos de "chá de revelação" disponibilizados no YouTube trouxe como contribuição atentarmos para a urgente necessidade de desconstruir convenções socioculturais que, embora sejam pensadas com a intenção de celebrar a chegada de uma nova vida, acaba por normatizar os corpos e gêneros das crianças, inserindo-os em categorias sociais bastante restritas. Se por um lado, uma quantidade significativa de vídeos do YouTube coloca em manutenção a força das (cishetero)normas, por outro lado, não podemos desconsiderar que essa rede social também constitui-se como uma plataforma importante de divulgação de informação que pode auxiliar educadoras/es na tarefa de construir práticas pedagógicas direcionadas para potencializar reflexões de gênero em sala de aula.

Seguimos nos rastros de Silva Junior, Caetano e Goulart (2018, p. 100) e acreditamos que a escola, por ser um dos primeiros núcleos sociais nos quais meninos e meninas se encontram ao sair da quase exclusividade do seio familiar, pode ser um campo fértil de resistência e acolhimento. Crianças de todas as idades, gêneros, raças, etnias e contextos socioculturais são

Revista Interinstitucional Artes de Educar. Rio de Janeiro, V. 6, N.2- pág. 469-488 maio-agosto de 2020: "Bebês e crianças: cultura, linguagem e políticas"

DOI: 10.12957/riae.2020.46467 
bombardeadas cotidianamente por diversas expectativas normativas que naturalizam formas cristalizadas de entender o que é ser "menino" e "menina". Essas práticas sociais (cishetero)normativas reforçam a compreensão estereotipada do gênero desde os primeiros anos da criança. Resistir ao regime heterocentrado também traz como implicação ética de acolhermos todas as crianças constantemente relegadas à experiência da abjeção por serem consideradas “diferentes". Essa prática do acolhimento precisa caminhar paralelamente ao nosso esforço de questionar todo e qualquer discurso preconceituoso e discriminatório que coloca em xeque a constituição de determinadas singularidades humanas.

A nosso ver, celebrar a vida não deveria se constituir em um rito envolvendo a reiteração de normas e convenções socioculturais que contribuem para reforçar os binarismos de gênero. Ademais, essas celebrações desconsideram outros gêneros para além dos já conhecidos feminino/masculino, ou seja, desconsideram o quanto cada nascimento traz consigo a irrupção da imprevisibilidade e da irreversibilidade. Cada criança que nasce é um desafio, uma interrupção, uma interrogação ao trazer consigo outras possibilidades de agir (RICHTER; BARBOSA, 2010, p. 86). Que cada nascimento permita-nos criar novas práticas educacionais, em parceria com as crianças, que sejam convidativas a outras formas de entender/ver o mundo. Precisamos reconhecer que as crianças constroem suas infâncias para muito além das dicotomias boneca/bola, delicada/bruto, rosa/azul, para citar alguns exemplos, muito embora haja um empreendimento considerável por parte das famílias e das instituições sociais para manter intacto o símbolo hegemônico do que é ser "menino" e "menina" na sociedade ocidental contemporânea. Essas reflexões caminham na mesma linha de pensamento de Adichie (2017, p. 26), para quem se não empregarmos a camisa de força do gênero nas crianças pequenas, daremos a elas espaço para alcançar todo seu potencial. No entanto, não somos ingênuos e reconhecemos o quão desafiante tem sido colocar em prática (des)ensinamentos em colaboração com as crianças, principalmente pelo fato de que muitas delas vêm sendo educadas/formadas em âmbitos familiares enraizados por valores homofóbicos, machistas, racistas e misóginos.

Adotar em sala de aula a postura de não desconstruir questões de gênero amplamente discutidas pelas crianças e outras/os educadoras/es, além de grave, vai na contramão da profissão docente, principalmente no que tange ao educar pensamentos e opiniões em uma sociedade crítica, democrática e inclusiva (GARCIA; BRITO, 2018, p. 1331). Que possamos subverter as normas regulatórias por meio de processos de ensinar-aprender que questionem a 
naturalização dos discursos por detrás dos processos de subalternização de determinados grupos sociais. Cabe, então, o desafio de planejarmos práticas pedagógicas que questionem uma ordem social e cultural que policia os corpos e nos impede de enxergar a infância, a educação, a vida e o mundo para além dos binarismos, que violam direitos e são produtores de práticas sexistas e racistas (SALGADO; MARTINS-GARCIA, 2018, p. 123). Que nossa ação docente seja potente para vislumbrarmos a multiplicidade de formas de nos constituirmos seres humanos, rebatendo discursos preconceituosos e discriminatórios que, desde a infância, bombardeiam incessantemente nossos corpos e gêneros.

\section{REFERÊNCIAS}

ADICHIE, C. N. Para educar crianças feministas: um manifesto. Tradução de Denise Bottmann. São Paulo: Companhia das Letras, 2017.

BELLO, A. T.; FELIPE, J. Delineando masculinidades desde a infância. Revista Instrumento, Juiz de Fora, v. 12, n. 2, jul./dez. 2010. Disponível em: 〈https://bit.ly/2L4XBRJ〉. Acesso em: 8 dez. 2018.

BENTO, B. Na escola se aprende que a diferença faz a diferença. Revista Estudos Feministas, Florianópolis, v. 19, n. 2, p. 549-559, maio/ago. 2011. Disponível em: <https://bit.ly/1VWhF9m >. Acesso em: 29 out. 2018.

BUTLER, J. Alianças queer e política anti-guerra. Bagoas - Estudos Gays: gênero e sexualidades, Natal, v. 11, n. 16, p. 29-49, 2017. Disponível em: 〈https://bit.ly/2Ni4w9G >. Acesso em: 20 set. 2018.

CARVALHO; F. S. P.; POCAHY, F.; SANTOS, E. Por uma formação não fascista: experimentações docentes na cibercultura. Revista Educativa, Goiânia, v. 20, n. 3, p. 752-768, set./dez. 2017. Disponível em: 〈https://bit.ly/2zOuk9t>. Acesso em: 7 dez. 2018.

CARVALHO; F. S. P.; ROSENO, R.; POCAHY, F. Vamos bater um bolo? Aquendações em rede nas tramas do envelhecimento. In: SEMINÁRIO INTERNACIONAL ENLAÇANDO SEXUALIDADES - SEXUALIDADES E RELAÇÕES DE GÊNERO: PRODUÇÃO E GESTÃO DO CONHECIMENTO, 5., 2017, Salvador. Anais... Salvador: Realize Eventos, 2017, $10 \mathrm{p}$.

COUTO JUNIOR, D. R. Cibercultura, juventude e alteridade: aprendendo- ensinando com o outro no Facebook. Jundiaí: Paco Editorial, 2013.

Revista Interinstitucional Artes de Educar. Rio de Janeiro, V. 6, N.2- pág. 469-488 maio-agosto de 2020: "Bebês e crianças: cultura, linguagem e políticas"

DOI: 10.12957/riae.2020.46467 


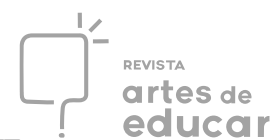

COUTO JUNIOR, D. R.; BRITO, L. T. "Vocês conhecem algumx 'heterossexual flexível'?": masculinidades performativas em debate. Educação Temática Digital, Campinas, v. 20, n. 1, p. 81-97, jan./mar. 2018. Disponível em: 〈https://bit.ly/2D0q3SY〉. Acesso em: 7 dez. 2018.

COUTO JUNIOR, D. R.; OSWALD, M. L. M. B. Cibercultura, juventudes e heteronormatividade: ativismo e resistência no Facebook. Revista Debates, Porto Alegre, v. 11, n. 2, p. 153-174, maio/ago. 2017. Disponível em: 〈https://bit.ly/2L6z3Ig>. Acesso em: 7 dez. 2018.

COUTO JUNIOR, D. R.; POCAHY, F. Dissidências epistemológicas à brasileira: uma cartografia das teorizações queer na pesquisa em educação. Inter-Ação, Goiânia, v. 42, n. 3, p. 608-631, set./dez. 2017. Disponível em: <https://bit.ly/2AsI62q>. Acesso em: 26 out. 2018.

FELIPE, J. Gênero, sexualidade e a produção de pesquisas no campo da educação: possibilidades, limites e a formulação de políticas públicas. Pro-Posições, Campinas, v. 18, n. 2, p. 77-87, maio/ago. 2007. Disponível em: 〈https://bit.ly/2N3iX2Z〉. Acesso em: 12 fev. 2019.

FERREIRA, H. M. C. Dinâmicas de uma juventude conectada: a mediação dos dispositivos móveis nos processos de aprender-ensinar. 2014. 272f. Tese (Doutorado em Educação) Faculdade de Educação, Universidade do Estado do Rio de Janeiro, Rio de Janeiro, 2014.

FERREIRA, H. M. C; COUTO JUNIOR, D. R. Juventudes, educação e cidade: a mediação dos dispositivos móveis de comunicação nos processos de aprender-ensinar. Textura, Canoas, v. 20, n. 44, p. 108-129, set/dez. 2018. Disponível em: 〈https://bit.ly/2PSO3ue〉. Acesso em: 6 dez. 2018.

FOUCAULT, M. História da sexualidade I: a vontade de saber. Tradução de Maria Thereza da Costa Albuquerque e J. A. Guilhon Albuquerque. São Paulo: Paz e Terra, 2014.

GARCIA, R. M.; BRITO, L. T. Performatizações queer na educação física escolar. Movimento, Porto Alegre, v. 24, n. 4, p. 1321-1334, out./dez. 2018. Disponível em: <https://bit.ly/2HQ9ahR>. Acesso em: 11 fev. 2019.

GUIZZO, B. S.; BECK, D. Q. Corpos depreciados: representações de gênero e geração na infância. Quaestio, Sorocaba, v. 16, n. 2, p. 297-313, nov. 2014. Disponível em: <https://bit.ly/2zN0qTz>. Acesso em: 7 mar. 2018.

JOBIM E SOUZA, S.; ALBUQUERQUE, E. D. P. A pesquisa em ciências humanas: uma leitura bakhtiniana. Bakhtiniana, São Paulo, v. 7, n. 2, p. 109-122, jul./dez. 2012. Disponível em: <https://bit.ly/2qu49A5>. Acesso em: 15 set. 2015.

LOURO, G. L. Foucault e os estudos queer. In: RAGO, M.; VEIGA-NETO, A. (Orgs.). Para uma vida não-fascista. Belo Horizonte: Autêntica, 2009, p. 135-143.

Revista Interinstitucional Artes de Educar. Rio de Janeiro, V. 6, N.2-pág. 469-488 maio-agosto de 2020: "Bebês e crianças: cultura, linguagem e políticas"

DOI: 10.12957/riae.2020.46467 
MACEDO, N. M. R. "Você tem face?" Sobre crianças e redes sociais online. 2014. 296f. Tese (Doutorado em Educação) - Faculdade de Educação, Universidade do Estado do Rio de Janeiro, Rio de Janeiro, 2014.

MEYER, D. E. Abordagens pós-estruturalistas de pesquisa na interface educação, saúde e gênero: perspectiva metodológica. In: MEYER, D. E.; PARAÍSO, M. A. (Orgs.). Metodologias de pesquisas pós-críticas em educação. 2. Ed. Belo Horizonte: Mazza Edições, 2014, p. 49-63.

MISKOLCI, R. Corpos elétricos: do assujeitamento à estética da existência. Estudos Feministas, Florianópolis, v. 14, n. 3, p. 681-693, set./dez. 2006. Disponível em: <https://bit.ly/2jhyRZH $>$. Acesso em: 7 mar. 2019.

PARAÍSO, M. A. Metodologias de pesquisas pós-críticas em educação e currículo: trajetórias, pressupostos, procedimentos e estratégicas analíticas. In: MEYER, D. E.; PARAÍSO, M. A. (Orgs.). Metodologias de pesquisas pós-críticas em educação. 2. Ed. Belo Horizonte: Mazza Edições, 2014, p. 25-47.

PEIXOTO, V. B. Violência contra LGBTs: premissas histórias da violação no Brasil. Periódicus, Salvador, v. 1, n. 10, p. 7-23, nov. 2017/abr. 2018. Disponível em: < https://bit.ly/2DKmX4a>. Acesso em: 17 fev. 2019.

PRADO FILHO, K.; TETI, M. M. A cartografia como método para as ciências humanas e sociais. Barbarói, Santa Cruz, n. 38, p. 45-59, jan./jun. 2013. Disponível em: <https://bit.ly/2QtXyVC>. Acesso em: 13 dez. 2018.

PRECIADO, P. B. Manifesto contrassexual: práticas subversivas de identidade sexual. Tradução de Maria Paula Gurgel Ribeiro. São Paulo: n-1 Edições, 2014.

RICHTER, S. R. S.; BARBOSA, M. C. S. Os bebês interrogam o currículo: as múltiplas linguagens na creche. Educação, Santa Maria, v. 35, n. 1, p. 85-96, jan./abr. 2010. Disponível em: 〈https://bit.ly/2DOAMzT>. Acesso em: 11 fev. 2019.

SALGADO, R. G.; MARTINS-GARCIA, P. F. Em nome dos cuidados, da proteção e da educação: infância, corpo, gênero e sexualidade como discursos entre professoras da Educação Infantil. Revista Zero-a-seis, Florianópolis, v. 20, n. 37, p. 112-124, jan./jun. 2018. Disponível em: 〈https://bit.ly/2GlnbTc >. Acesso em: 11 fev. 2019.

SANTOS, E.; CARVALHO, F. S. P. Autorias partilhadas na interface cidade-redes digitais. Interfaces Científicas - Educação, Aracaju, v. 6, n. 3, p. 29-40, jun. 2018. Disponível em: <https://bit.ly/2MQHAOF>. Acesso em: 20 jul. 2018.

SANTOS, E.; WEBER, A. Educação e cibercultura: aprendizagem ubíqua no currículo da disciplina didática. Revista Diálogo Educacional, Curitiba, v. 13, n. 38, p. 285-302, jan./abr. 2013. Disponível em: 〈https://bit.ly/2MQrvZt >. Acesso em: 20 set. 2018.

Revista Interinstitucional Artes de Educar. Rio de Janeiro, V. 6, N.2-pág. 469-488 maio-agosto de 2020: "Bebês e crianças: cultura, linguagem e políticas" 
SILVA JUNIOR, P. M.; CAETANO, M.; GOULART, T. E. S. "Ele queria ser a Cinderela": construções queer à leitura das masculinidades no Ensino Fundamental. Periódicus, Salvador, v. 1, n. 9, p. 87-104, maio/out. 2018. Disponível em: <https://bit.ly/2G5adsq>. Acesso em: 11 fev. 2019.

\footnotetext{
${ }^{\text {i }}$ Pós-doutorando (bolsista PNPD/CAPES) e professor no Programa de Pós-Graduação em Educação, Cultura e Comunicação em Periferias Urbanas (PPGECC) da Universidade do Estado do Rio de Janeiro/Baixada Fluminense (UERJ/FEBF). Membro do Núcleo de Estudos Diferenças, Educação, Gênero e Sexualidades (NUDES). E-mail: junnior_2003@yahoo.com.br / ORCID: http://orcid/org/0000-0002-5221-7135

ii Professor da Faculdade de Educação da Baixada Fluminense e do Programa de Pós-Graduação em Educação, Cultura e Comunicação em Periferias Urbanas (PPGECC) da Universidade do Estado do Rio de Janeiro/Baixada Fluminense (UERJ/FEBF). Líder do Núcleo de Estudos Diferenças, Educação, Gênero e Sexualidades (NUDES). Email: ivanamaro.uerj@ gmail.com / ORCID: http://orcid.org/0000-0002-8813-5510

iii Mestrando no Programa de Pós-Graduação em Educação, Cultura e Comunicação em Periferias Urbanas (PPGECC) da Universidade do Estado do Rio de Janeiro/Baixada Fluminense (UERJ/FEBF). Membro do Núcleo de Estudos Diferenças, Educação, Gênero e Sexualidades (NUDES). E-mail: renatoromeritto@gmail.com / ORCID: http://orcid.org/0000-0002-7750-1538
}

iv Mestrando no Programa de Pós-Graduação em Educação, Cultura e Comunicação em Periferias Urbanas (PPGECC) da Universidade do Estado do Rio de Janeiro/Baixada Fluminense (UERJ/FEBF). Membro do Núcleo de Estudos Diferenças, Educação, Gênero e Sexualidades (NUDES). E-mail: rmruani@yahoo.cl / ORCID: http://orcid.org/0000-0002-6712-9285

v As (cishetero)normas dizem respeito às normas regulatórias de gênero que agem sobre todos os corpos, independente da orientação sexual ou da identidade de gênero. No entanto, tais normas agem de forma mais brutal sobre todos os corpos que "desviam" de aspectos sociais considerados padrão, como a orientação sexual heterossexual e a cisgeneridade (a pessoa cisgênero é aquela que se identifica com o gênero que the foi atribuído no ato do nascimento).

Revista Interinstitucional Artes de Educar. Rio de Janeiro, V. 6, N.2- pág. 469-488 maio-agosto de 2020: "Bebês e crianças: cultura, linguagem e políticas"

DOI: 10.12957/riae.2020.46467 